\title{
A STUDY STRATEGIES SELF-EFFICACY INSTRUMENT FOR USE WITH COMMUNITY COLLEGE STUDENTS
}

\author{
BETHANY B. SILVER \\ Naugatuck Valley Community-Technical College \\ EVERETT V. SMITH, JR. \\ University of Illinois at Chicago \\ BARBARA A. GREENE \\ University of Oklahoma
}

\begin{abstract}
Theories of self-efficacy and self-regulation were used to examine scores from an instrument that measures self-efficacy for using self-regulatory study strategies. The authors investigated the dimensionality of responses to the Study Skills Self-Efficacy Scale using exploratory factor analysis and Rasch measurement. They also investigated the utility of the Rasch measures in differentiating between groups of students who report being academically successful or at risk. The participants were 550 social science students at a midsized northeastern community-technical college. Results indicated that responses define three related dimensions and that measures were able to differentiate between students reporting to be academically successful or at risk. Additional items need to be developed to increase measurement precision along various portions of the self-efficacy dimensions.
\end{abstract}

Although there is considerable evidence that self-efficacy is a key construct for explaining academic achievement (e.g., Ames \& Archer, 1988; Greene \& Miller, 1996; Meece, Blumenfeld, \& Hoyle, 1988; Miller, Behrens, Greene, \& Newman, 1993; Miller, Greene, Montalvo, Ravindran, \& Nichols, 1996; Pajares \& Miller, 1994; Pintrich \& DeGroot, 1990; Zimmerman \& Bandura, 1994; Zimmerman \& Martinez-Pons, 1990), we still know rela-

Correspondence about this article should be addressed to Everett Smith, College of Education, Department of Educational Psychology, University of Illinois at Chicago, 1040 W. Harrison Street, M/C 147, Chicago, IL 60607; e-mail: evsmith@uic.edu.

Educational and Psychological Measurement, Vol. 61 No. 5, October 2001 849-865 (C) 2001 Sage Publications 
tively little about how the construct can be used to facilitate achievement or, at least, motivation to learn. The convergence of research on self-efficacy and self-regulation (cf. Schunk, 1991; Zimmerman, 1989; Zimmerman, Bandura, \& Martinez-Pons, 1992) could provide the foundation for more applied research in this area. In this vein, the present study was designed to examine some psychometric properties of scores from an instrument that measures self-efficacy for using self-regulatory study strategies.

Self-efficacy theory (Bandura, 1986; Schunk, 1991) maintains that students' self-perceptions of ability (i.e., efficacy beliefs) should be positively related to their level of cognitive engagement in a task. Importantly, self-efficacy is defined as the confidence one has for successfully completing a specific task (Bandura, 1986), so self-efficacy is different from a more general construct of self-concept. As Pajares (1996) noted, many self-concept measures are far too general to demonstrate the theorized predictive relationship between outcome and self-efficacy. The task-specificity aspect of self-efficacy makes sense when the relationship of self-efficacy to cognitive engagement is considered.

As Schunk (1991) has argued, when students have successfully used cognitive strategies in past learning situations that are similar to current situations, their self-efficacy in the current situation should be high. Similarly, when students feel efficacious in learning situations, they are more likely to use strategies and persist in strategy use than when they have low self-efficacy. Consistent with these theoretical predictions, a substantial body of research has shown that self-efficacy is positively related to level of cognitive engagement and achievement (e.g., Ames \& Archer, 1988; Greene \& Miller, 1996; Miller et al., 1993; Miller et al., 1996; Pajares \& Miller, 1994; Pintrich \& DeGroot, 1990; Zimmerman \& Bandura, 1994; Zimmerman \& MartinezPons, 1990).

The link between level of cognitive engagement and achievement has also been well established (e.g., Brown, Bransford, Ferrara, \& Campione, 1983; Harris \& Pressley, 1991; Pressley, Borkowski, \& Schneider, 1987; Zimmerman, 1989; Zimmerman \& Martinez-Pons, 1990). Level of cognitive engagement refers to the amount and type of self-regulatory and strategy knowledge used in learning situations. The existing research demonstrates that self-regulation of learning and the use of learning strategies are critical components of successful learning. In addition, strategies that encourage meaningful processing (i.e., establishing connections between prior knowledge and the new information) are found to be more associated with successful learning than are strategies that encourage shallow or rote strategies (Greene \& Miller, 1996; Nicholls, 1989; Nolen, 1988; Pintrich \& Garcia, 1991; Weinstein \& Mayer, 1986). Because one's level of self-efficacy is related to one's level of 
cognitive engagement, problems with self-efficacy may be a way to explain why students fail to use strategies that they seem to possess.

Pressley (1995) recently noted that although self-regulatory strategies for academic studying can be easily taught, use of those strategies often does not transfer to nontraining settings even when training has attempted to foster transfer of strategy use. One plausible explanation is that a person's self-efficacy does not encourage the use of new cognitive strategies. It could be that self-efficacy for learning in a particular domain, or for a particular learning task, is too low to warrant the extra effort required by the strategy, or it could be that self-efficacy for effectively using the strategy itself is low. Most researchers examine self-efficacy in relation to specific domains and learning tasks. The relatively few studies that have examined self-efficacy related to the use of study strategies have provided evidence for the importance of selfefficacy specific to self-regulatory strategies (e.g., Borkowski, Carr, Rellinger, \& Pressley, 1990; Boyle, 1997; Williams, 1996; Zimmerman et al., 1992).

We thought that further study of how to measure self-efficacy for strategy use might yield a tool that could be used in conjunction with strategy-training interventions. Although interventions have typically included an assessment of whether the trained strategies were learned, they typically do not assess whether the trained strategies will be used in novel settings. As Lusardi and Smith (1997) argued, self-efficacy measures can be better indicators of the intent to use, and persistence in using, recently acquired knowledge than the outcome measures used considering that knowledge that has been learned (outcome measures) is not evidence that knowledge will be applied.

In addition, we thought that a community college population would be appropriate for such an assessment. A recent study by Douzenis (1997) found that degree and quality of effort in academic activities was related to community college students' estimates of knowledge gained. Because a history of academic struggles is a common reason why students choose to attend community colleges as opposed to 4-year colleges, these students typically will be in need of some type of study strategy intervention before they can put forth quality effort. Grunder and Hellmich (1997) provided some evidence for the effectiveness of an intervention that attempted to link study skills, time management skills, goal assessment, and academic success. However, Grunder and Hellmich did not provide an explanation for when the intervention was not effective. We felt that a measure of self-efficacy for study skill use could provide for this explanation. Therefore, we chose to use the Study Skills Self-Efficacy Scale (SSSES) adapted by Silver, Gable, and Smith (1995) for community college students to examine the dimensionality and utility of scores from that instrument. Several recent studies have provided 
evidence for the reliability and validity of scores obtained using various versions of this instrument (Ramirez \& Owen, 1991; Silver et al., 1995; Silver, Gunther, Smith, \& Owen, 1996; Smith, Owen, Reid, \& Ramirez, 1990).

Development of the original SSSES began with a 63-item instrument designed to measure self-efficacy for study skills (Smith et al., 1990) for college-level and graduate populations. Smith et al. (1990) chose items primarily based on Zimmerman's (1989) 15 categories for self-regulated learning strategies and Schmeck, Ribich, and Ramanaiah's (1977) work on learning preferences. The researchers examined, with a sample of 245 undergraduate students, whether study skills self-efficacy would be a significant predictor of self-reported GPA when gender, semester standing, and expected course grade were also in the regression equation. Data indicated that study skills self-efficacy, expected course grade, and semester standing were statistically significant predictors of self-reported grade. Participants who reported higher study skills self-efficacy expected better grades, had completed more semesters, and reported higher GPAs.

Further revision of the scale was done by Ramirez and Owen (1991) who, with a sample of 305 college students, first submitted scores from the instrument to a principal component factor analysis with an oblique solution. The researchers identified five factors: Conceptual Skill (16 items), Memorization (8 items), Study Routines (11 items), Self Modification (7 items), and Use of Auxiliary Materials (5 items). The Conceptual Skill category contained items similar to what others have called "elaboration" (Schmeck et al., 1977) or "meaningful learning" (Greene \& Miller, 1996). Ramirez and Owen noted that their five factors could be further collapsed into the three aspects of self-regulation described by Zimmerman (Zimmerman, 1989; Zimmerman \& Martinez-Pons, 1990). The "personal" aspect of self-regulatory functioning is captured by the factors Conceptual Skill and Memorization, the "behavioral" aspect of self-regulatory functioning is captured by the Self Modification factor, and the "environmental" aspect is captured by the factors Study Routines and Use of Auxiliary Materials. With a new sample of 150 university undergraduate and graduate students, Ramirez and Owen also examined which of the five factors might predict self-reported GPA when gender, semester standing, and expected course grade were also in the regression equation. Ramirez and Owen found that Study Routines and Memorization were statistically significant predictors beyond semester standing and expected course grade.

We extended this research by first examining the dimensionality of responses to the SSSES using a combination of exploratory factor analysis and Rasch measurement. Second, we evaluated whether the obtained measures could be used to differentiate between students expecting As and Bs and those expecting Cs and Ds as regular grades. 


\section{Method}

\section{Instrumentation and Sample}

For this study, the scale was adapted for a community college sample. Fourteen of the 47 items from Ramirez and Owen (1991) were retained in their exact language; 11 items were modified for appropriate reading level, syntax, or content; and 22 items were not used as they referred to activities more appropriate for a university setting. In addition, 7 items were added to address issues specific to the community-technical college site, for a total of 32 items. Participants responded to the items by indicating their degree of confidence for successfully engaging in each of the specific study strategies. More specifically, participants answered the question, "How much confidence do you have in doing these behaviors?" The response format consisted of a 5-point Likert-type confidence scale with the extremes labeled very little and quite a lot. Participants were also asked to indicate what grades they normally receive using the following scale: 100-90 (A), 89-80 (B), 79-70 (C), 69-60 (D), and below 60 (F). Due to low category use, we dichotomized the self-reported normally received grades. The first group consisted of those reporting As and Bs as normal grades. We considered this group to be academically successful. The second group consisted of those reporting Cs or Ds as normal grades. These students were considered academically less successful.

The resulting scale (see the appendix for item content) was administered to 550 social science students at a midsize northeastern community-technical college in the spring of 1995 . Students were enrolled in introductory psychology, anthropology, and sociology courses. No course credit was given for participation. The mean age of participants was 24.72 years $(S D=8.66$ years). The average number of college courses taken was 9.67 ( $S D=9.34$ courses). Data concerning gender were not available.

\section{Analyses}

An exploratory common factor analysis with oblique rotation was used to initially investigate the dimensionality of the data. We chose the common factor model over principal components as our interest is in a theoretical solution with unique and error variability removed rather than an empirical summary of the data (Tabachnick \& Fidell, 1996). The Rasch rating scale model (Andrich, 1978; Wright \& Masters, 1982) was then used to further explore dimensionality, produce estimates of person and item score reliability, and provide person measures for subsequent statistical analyses. The factor analysis was used prior to the Rasch calibrations to identify potential sets of items 
(i.e., those items defining each factor) that may meet the unidimensionality requirement of Rasch measurement models as the previous reviewed research has demonstrated that responses to various versions of the SSSES represent a multidimensional construct. A MANOVA was then employed to detect any reliable differences between students reporting As and Bs as typical grades versus those reporting Cs and Ds on the vector of self-efficacy measures obtained from the Rasch analyses. Given reliable differences, descriptive discriminant function analysis (DFA) was used as a post hoc method to investigate which measures were separating the two groups.

\section{Results}

\section{Common Factor Analysis}

A common factor analysis based on 503 complete sets of data was used to extract three factors using a combination of Kaiser's criterion and a scree plot. These three factors accounted for $77.47 \%$ of the common item covariance. The three factors, following oblique rotation, were labeled Study Routines (16 items, $50.97 \%$ of the common item covariance), Text-Based Critical Thinking (11 items, $16.42 \%$ of the common item covariance), and Resource Use ( 5 items, $10.08 \%$ of the common item covariance). Factor intercorrelations ranged from .371 to .379 . The pattern and structure coefficients, eigenvalues, and factor intercorrelations are displayed in Table 1. Of special interest is the loss of a factor, labeled Self Modification by Ramirez and Owen (1991), between the university and community-technical college populations. Items relating to Self Modification and Study Routines from the Ramirez and Owen instrument collapsed into a general Study Routines factor for the present community-technical sample. These items relate to acknowledging and rewarding oneself for having studied hard or prepared well for a test.

\section{Rasch Analyses}

Each set of items corresponding to the factors described previously were subjected to separate Rasch analyses using BIGSTEPS (Linacre \& Wright, 1995). BIGSTEPS provides two fit statistics: infit and outfit. The infit statistic is insensitive to unexpected responses to items far from a person's selfefficacy level, whereas outfit is sensitive to unexpected ratings far from a person's level of self-efficacy. When reported as mean squares, which is simply a chi-square divided by the appropriate degrees of freedom, these fit statistics have an expected value of one with a range from zero to infinity. Mean square fit statistics less than one indicate redundancy, dependency, or constriction of data. Mean squares greater than one are indicative of unexpected variability, 
Table 1

Pattern/Structure Coefficients and Factor Intercorrelations

\begin{tabular}{|c|c|c|c|}
\hline Item & $\begin{array}{c}\text { Study } \\
\text { Routines }\end{array}$ & $\begin{array}{c}\text { Text-Based } \\
\text { Critical } \\
\text { Thinking }\end{array}$ & $\begin{array}{l}\text { Resource } \\
\text { Use }\end{array}$ \\
\hline Maintaining a daily schedule of study hours. & $.751 / .705$ & $-.070 / .188$ & $-.054 / .202$ \\
\hline Having regular, weekly review periods. & $.730 / .694$ & $-.084 / .182$ & $-.012 / .230$ \\
\hline Having a regular place to study. & $.627 / .603$ & $.021 / .221$ & $-.085 / .159$ \\
\hline $\begin{array}{l}\text { Balancing my study time according to the } \\
\text { demands of different classes. }\end{array}$ & $.601 / .644$ & $.162 / .368$ & $-.046 / .242$ \\
\hline Making an outline of material covered in a course. & $.561 / .607$ & $.073 / .300$ & $.050 / .289$ \\
\hline Praising myself for doing a good job studying. & $.545 / .525$ & $-.078 / .133$ & $.023 / .198$ \\
\hline Evaluating my progress at each step. & $.539 / .594$ & $.066 / .297$ & $.080 / .308$ \\
\hline Having a place to study without distractions. & $.514 / .512$ & $.031 / .208$ & $-.035 / .170$ \\
\hline Treating myself after doing well on a test. & $.509 / .489$ & $-.120 / .094$ & $.066 / .212$ \\
\hline $\begin{array}{l}\text { Making up possible test questions from notes and } \\
\text { readings. }\end{array}$ & $.485 / .505$ & $.031 / .219$ & $.023 / .217$ \\
\hline $\begin{array}{l}\text { Reviewing and revising my notes shortly after } \\
\text { taking them. }\end{array}$ & $.472 / .508$ & $.092 / .269$ & $.005 / .218$ \\
\hline Completing assignments on time. & $.410 / .434$ & $.140 / .264$ & $-.075 / .132$ \\
\hline Rewarding myself for studying by taking a break. & $.404 / .426$ & $.006 / .175$ & $.050 / .205$ \\
\hline Doing well in school. & $.385 / .533$ & $.410 / .548$ & $-.011 / .289$ \\
\hline Asking a friend to read my work before handing it in. & $.322 / .371$ & $-.068 / .127$ & $.199 / .294$ \\
\hline Reading assignments out loud before handing them in. & $.298 / .386$ & $.024 / .214$ & $.209 / .330$ \\
\hline Reading critically. & $-.100 / .182$ & $.694 / .681$ & $.066 / .291$ \\
\hline Understanding what I read in a textbook. & $-.025 / .270$ & $.682 / .665$ & $-.021 / .228$ \\
\hline Taking tests that ask me to compare different concepts. & $.029 / .235$ & $.632 / .614$ & $-.077 / .174$ \\
\hline Taking tests that require critical evaluation. & $.024 / .248$ & $.627 / .628$ & $-.021 / .226$ \\
\hline $\begin{array}{l}\text { Figuring out the meaning of new words from their } \\
\text { context. }\end{array}$ & $.037 / .258$ & $.564 / .590$ & $.032 / .260$ \\
\hline Taking ess & $-.078 / .165$ & $.552 / .562$ & $.102 / .282$ \\
\hline Finding the right word for expressing my ideas. & $-.044 / .149$ & $.532 / .571$ & $-.012 / .173$ \\
\hline $\begin{array}{l}\text { Writing a summary of the important points from } \\
\text { something I read. }\end{array}$ & $.070 / .298$ & $.517 / .580$ & $.096 / .319$ \\
\hline Relating what I read to other information. & $.138 / .366$ & $.511 / .601$ & $.101 / .347$ \\
\hline Figuring out practical applications for new concepts. & $.014 / .229$ & $.488 / .528$ & $.092 / .282$ \\
\hline Summarizing what I read in my own words. & $.260 / .398$ & $.375 / .471$ & $-.003 / .237$ \\
\hline Using the reference books at the library. & $.035 / .356$ & $.054 / .371$ & $.802 / .836$ \\
\hline Using the card catalogue at the library. & $-.055 / .265$ & $.055 / .337$ & $.797 / .797$ \\
\hline Using a computer reference system at the library. & $-.030 / .222$ & $-.006 / .240$ & $.676 / .663$ \\
\hline Using a thesaurus. & & & $.531 / .623$ \\
\hline Using a dictionary. & $.244 / .423$ & $.086 / .325$ & $.393 / .517$ \\
\hline
\end{tabular}

Factor intercorrelation matrix

Study Routines Text-Based Critical Thinking

Text-based critical thinking $\quad .37$

$\begin{array}{lll}\text { Resource use } & .376 & .379\end{array}$

Note. Pattern coefficients are presented first followed by structure coefficients. Coefficients deemed salient for a given factor are underlined. 
inconsistency, or extremism. An acceptable range for both infit and outfit mean square fit statistics is 0.6 to 1.4 (Wright \& Linacre, 1994). In addition to the validity of data-model fit, an index of reliability is also provided. In Rasch measurement, this estimate is the person separation reliability index. It is an indication of the spread of person self-efficacy measures along the self-efficacy continuum and is analogous in interpretation to coefficient alpha in true score theory. There is a complementary reliability index for items that indicates the extent to which the item calibrations are spread over the self-efficacy continuum.

The specific Rasch model employed for the current investigation was the rating scale model (Andrich, 1978; Wright \& Masters, 1982). This model is appropriate for estimating person abilities and item difficulties for responses scored in at least two or more ordered categories (Wright \& Masters, 1982). For the rating scale model, a self-efficacy measure for each person, a set of category threshold parameters common to each item, and item endorsability parameters are estimated. This model assumes that the rating scale functions in a similar manner across all items.

Calibration of the 16 Study Routine items found Item 29 to misfit (mean square infit $=1.7$, mean square outfit $=1.49$ ). This item displayed more variability than expected by the model. Examination of item content indicated a potential problem. Item 29 states, "Asking a friend to read my work before handing it in." Two concepts appear to be operating: "asking a friend" and "reading work prior to handing the work in." This item needs to be modified for future versions of the scale. Removal of this item and calibration of the remaining 15 items found Item 28 , "Reading assignments out loud before handing them in," had a mean square infit of 1.41 and mean square outfit of 1.49. The wording "out loud" may be the cause of the excessive variability. Perhaps these participants view reading to oneself out loud to be a silly activity when the same type of practice may be achieved by simply reading silently to oneself. Again, this item appears to need modification. These 2 items also had the lowest pattern and structure coefficients from the 16 items constituting the Study Routines dimension.

Calibration of the remaining 14 items demonstrated acceptable fit to the model (range mean square infit $=0.67$ to 1.30 ; range mean square outfit $=$ 0.67 to 1.30$)$. The average person measure was $0.28 \operatorname{logits}(S D=0.85)$. The person separation reliability of 0.85 indicated that the self-efficacy estimates were well dispersed along the self-efficacy continuum. The standard deviation of the item calibrations was 0.57 . There was a good match between the distributions of self-efficacy estimates and item calibrations. This can be seen visually in the variable map displayed in Figure 1 as the considerable overlap between the distribution of the self-efficacy estimates on the left side of the figure and the distribution of the item calibration on the right side. For persons, higher logit values indicate more self-efficacy; higher logit values 
for items indicate items that are more difficult to endorse. Item separation reliability was .99 , indicating that the items are well spread out over the selfefficacy continuum. The rating scale appears to be functioning in the manner intended, as indicated by the ordered average measures $(-0.93,-0.42,0.16$, 0.68 , and 1.25, corresponding to the observed categories of $1,2,3,4$, and 5, respectively) and ordered step calibrations $(-1.25,-0.50,0.40$, and 1.35). Average measures represent the average of the logit measures that were estimated to produce the responses observed in each category. For example, if one participant circled " 1 " eight times, then this participant's measure would contribute eight times in the calculation of the average measure for the category of 1 . Ordered step calibrations imply that as one moves up the self-efficacy continuum, each category in turn becomes the most probable response.

Calibration of the 11 items from the Text-Based Critical Thinking dimension found Item 32, "Summarizing what I read in my own words," to have a mean square infit of 1.46 and a mean square outfit of 1.45 . This item also had the lowest pattern and structure coefficients on the Text-Based Critical Thinking dimension. Removal of this item and calibration of the remaining 10 items found Item 9, "Taking essay tests," to display excessive variability (mean square infit $=1.50$; mean square outfit $=1.50$ ). Taking essay tests seems to convey different meanings to different participants. The remaining 10 items have acceptable fit to the model (range of mean square infit $=0.82$ to 1.26; range of mean square outfit $=0.83$ to 1.24 ). The average person measure was $0.76 \operatorname{logits}(S D=1.28)$. The person separation reliability was 0.82 . The standard deviation of the item calibrations was 0.42 . Item separation reliability was 0.98 .

Figure 2 displays the variable map for Text-Based Critical Thinking. Notice that the extremes of the self-efficacy distribution do not have corresponding items in the same relative location. This lack of overlap contributes to less measurement precision for the measures in either extreme of the person distribution. Items need to be developed to assess these portions of the self-efficacy continuum. Average measures and step calibrations were ordered $-1.48,-0.50,0.34,1.30$, and 2.38 and $-2.56,-1.14,0.94$, and 2.77 for measures and calibrations, respectively.

The five items from the Resource Use dimension displayed accepted fit (range of mean square infit $=0.68$ to 1.21 ; range of mean square outfit $=0.71$ to 1.24). The average person measure was $0.11 \operatorname{logits}(S D=1.19)$. The person separation reliability was 0.72 . The low person separation reliability is primarily due to the relative few items composing this scale. The standard deviation of the item calibrations was 0.44 . Item separation reliability was 0.99 . Figure 3 displays the variable map for Resource Use. Large gaps existed among the item calibrations, indicating low measurement precision along much of the continuum. Items need to be developed to assess these portions of the self-efficacy continuum. Average measures and step calibrations were 


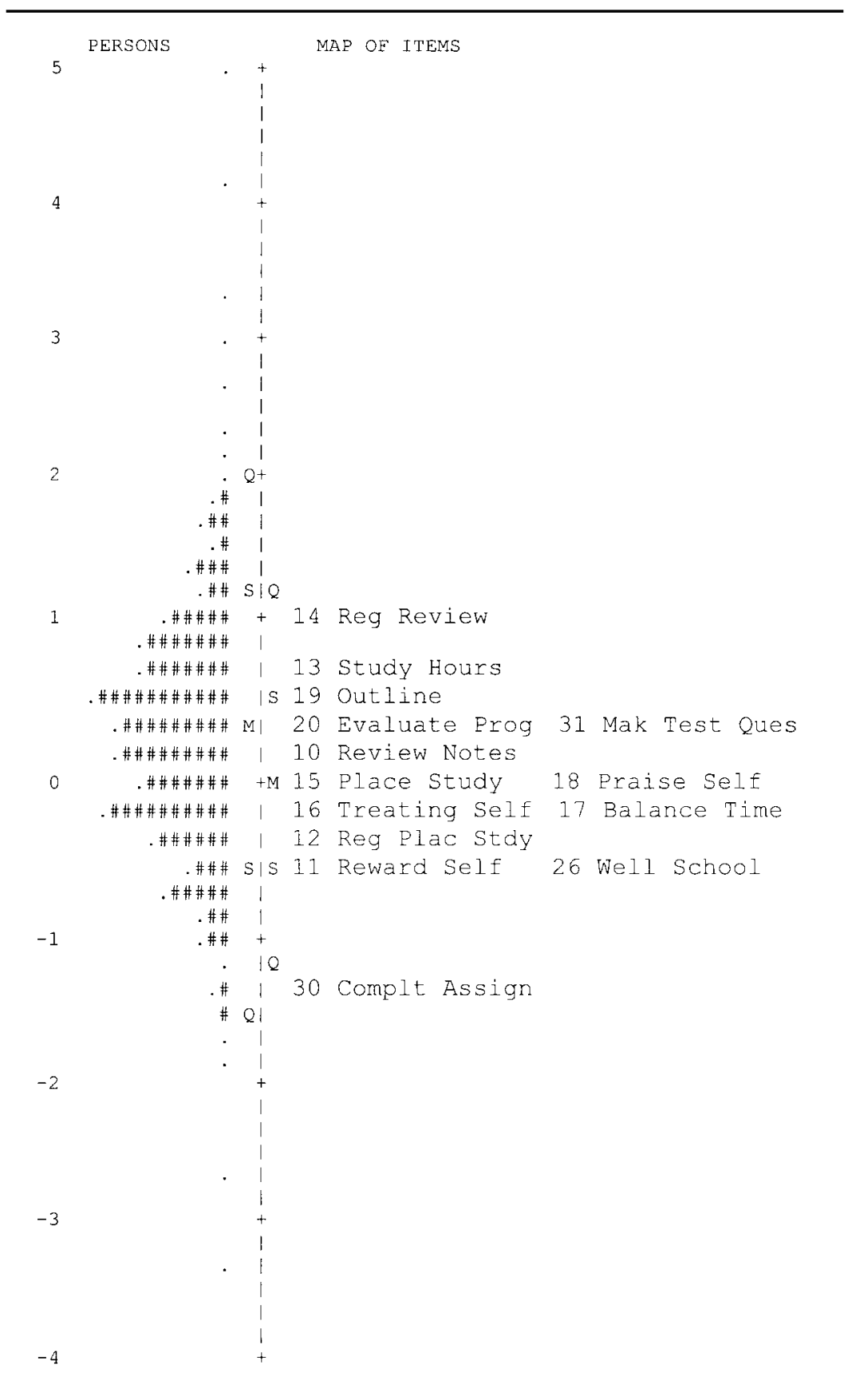

Figure 1. Variable map of person measures and item calibrations for Study Routines. Note. $\mathrm{M}=$ mean; $\mathrm{S}=$ one standard deviation; $\mathrm{Q}=$ two standard deviations. See the appendix for complete item content. Each "\#”' is 5 persons; each ".." is 1 to 4 persons. 
SILVER ET AL.

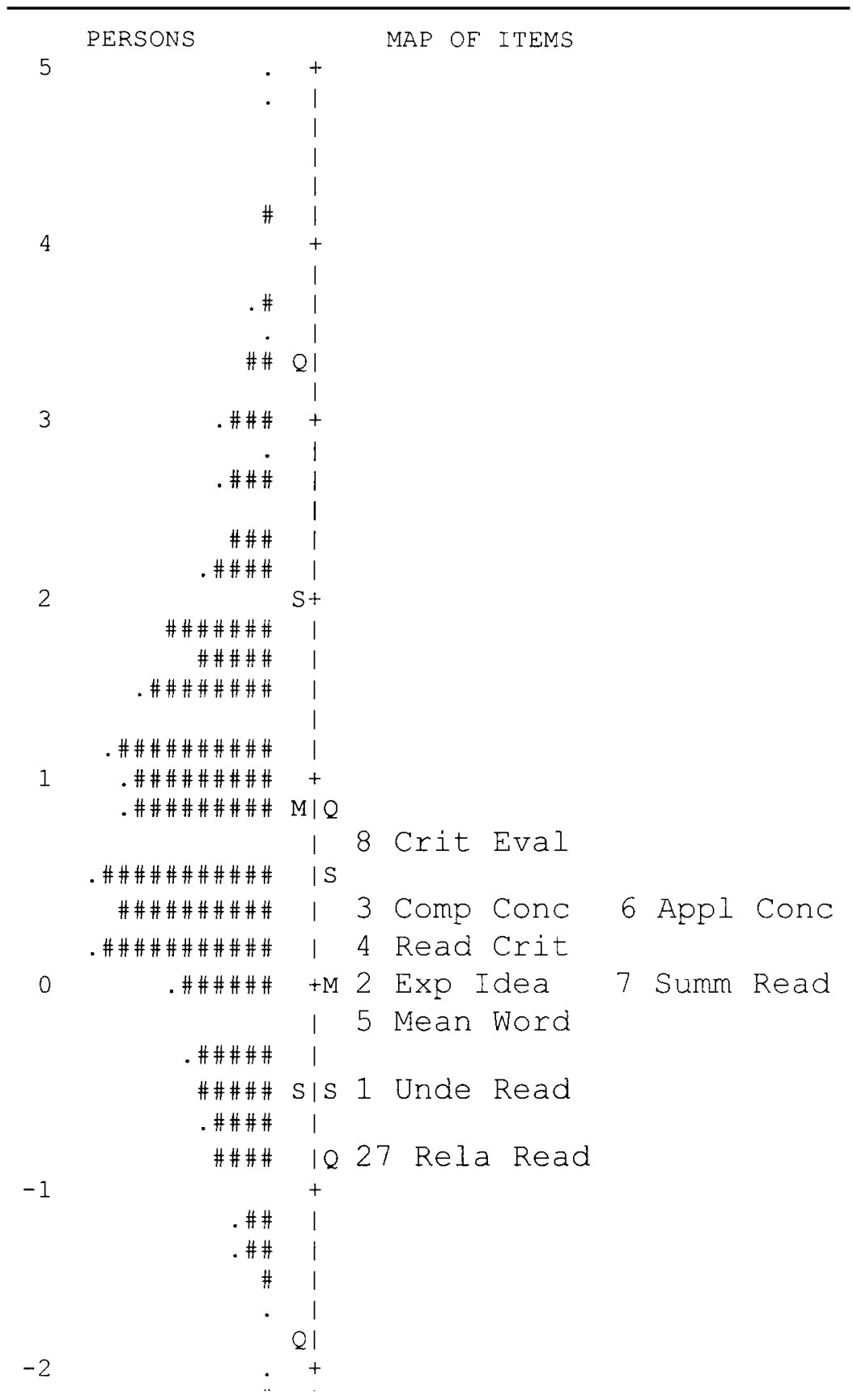

Figure 2. Variable map of person measures and item calibrations for Text-Based Critical Thinking.

Note. $\mathrm{M}=$ mean; $\mathrm{S}=$ one standard deviation; $\mathrm{Q}=$ two standard deviations. See the appendix for complete item content. Each "\#” is 4 persons; each “." is 1 to 3 persons. 


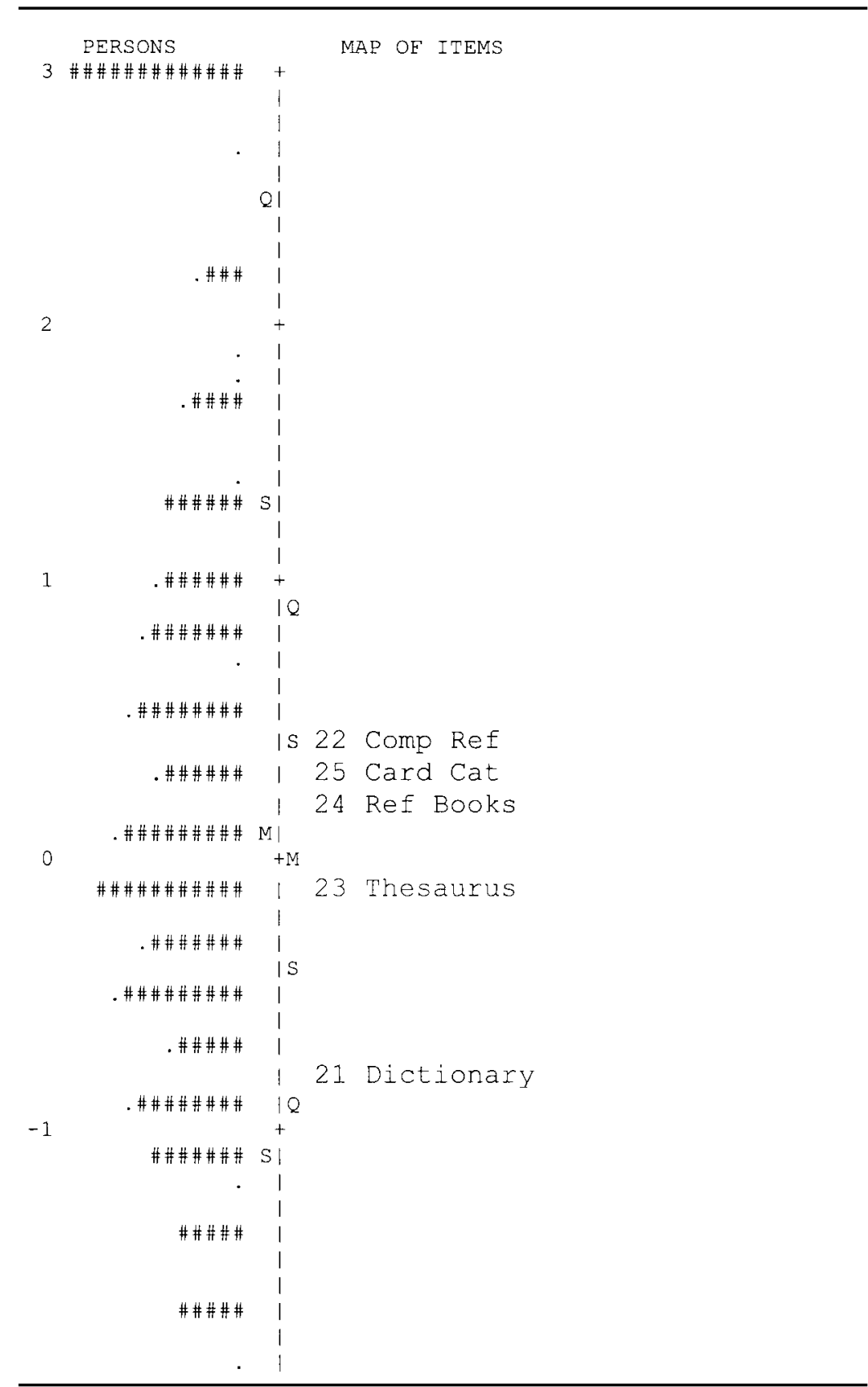

Figure 3. Variable map of person measures and item calibrations for Resource Use.

Note. $\mathrm{M}=$ mean; $\mathrm{S}=$ one standard deviation; $\mathrm{Q}=$ two standard deviations. See the appendix for complete item content. Each "\#” is 4 persons; each "." is 1 to 3 persons. 
Table 2

Means (standard deviations) of Rasch Self-Efficacy Measures for High and Low Self-

Reported Grade Groups

\begin{tabular}{lcccc}
\hline \hline & \multicolumn{4}{c}{ Self-Reported Grades } \\
\cline { 2 - 5 } & \multicolumn{2}{c}{ As and Bs } & Cs and Ds \\
\hline$n$ & \multicolumn{2}{c}{399} & \multicolumn{2}{c}{132} \\
Dimension & & & & \\
Study Routines & 0.44 & $(0.87)$ & -0.13 & $(0.79)$ \\
Text-Based Critical Thinking & 0.91 & $(1.27)$ & 0.29 & $(1.18)$ \\
Resource Use & 0.35 & $(1.53)$ & -0.20 & $(1.40)$ \\
\hline
\end{tabular}

Note. There were more participants in the Rasch analyses, MANOVA, and discriminant function analysis as compared to the exploratory factor analysis (EFA). The EFA used only cases with complete data, whereas Rasch models yielded estimates for cases with either complete or incomplete data.

ordered $-1.22,-0.68,-0.04,0.67$, and 1.54 (measures) and $-0.97,-0.63$, 0.24 , and 1.35 (calibrations).

\section{MANOVA and Descriptive DFA}

The relationship between study strategies self-efficacy and self-reported grades was examined using a MANOVA with the three Rasch measures serving as the dependent variables and the independent variable being normal grades (self-reported $\mathrm{A}$ and $\mathrm{B}$ grades versus $\mathrm{C}$ and $\mathrm{D}$ grades). The equality of covariance matrices assumption was tenable, Box's $M=6.656, F(6,368762)=$ $1.099, p=.36$. Statistically significant differences and a meaningful effect size were found between the two groups, Wilks's lambda $=.911, F(3,527)=$ $17.24, p<.001$, eta square $=.09$. As reported in Table 2 , those reporting higher grades had substantially higher levels of self-efficacy across all three dimensions.

A descriptive DFA (using prior probabilities based on group sample sizes) was used as a post hoc procedure to investigate which self-efficacy measures were contributing to the group differences. The standardized function (and structure) coefficients were .769 (.931) for Study Routines, .362 (.681) for Text-Based Critical Thinking, and .073 (.510) for Resource Use. The standardized (beta weights) and structure (correlations) coefficients are consistent in the rank ordering of the measures, with Study Routines being the best measure to separate the two groups and Resource Use the least useful.

\section{Discussion}

The foregoing data provide some initial support for the dimensionality of the responses to the revised SSSES. The identified subscale scores differenti- 
ated between students reporting Cs and Ds and those reporting As and Bs. Consistent with the theoretical framework described by Bandura (1986) and Zimmerman (1989), this finding shows that although the instrument measures self-efficacy, those measures are related to outcome measures, supporting the link between self-efficacy and achievement. However, additional work appears warranted to increase measurement precision in portions of the self-efficacy continuum. In particular, new items are needed to increase the measurement precision over a wider range of the self-efficacy continuum.

The present study's primary intention was to examine self-efficacy for study skills in the community-technical college population. Our long-term aim is to positively influence success in postsecondary learning environments. To this end, the instrument will be further developed and then used as a prescriptive measure. Further development will include more sources of validity evidence to support that scores from the instrument truly measure self-efficacy (and not frequency of use, for example), including investigations of the relationships of SSSES scores with measures of effort, goal orientation, perceived future consequences, and persistence. To study the prescriptive component, students entering the community-technical college will be administered the instrument, and a diagnostic and prescriptive program of study skills instruction will be designed to enhance self-efficacy for study skills. These future research efforts will include objective measures of achievement and multiple procedures for evaluating the effectiveness of intervention programs.

Appendix

Item Content of the Study Skills Self-Efficacy Scale

1. Understanding what I read in a text book.

2. Finding the right word for expressing my ideas.

3. Taking tests that ask me to compare different concepts.

4. Reading critically.

5. Figuring out the meaning of new words from their context.

6. Figuring out practical applications for new concepts.

7. Writing a summary of the important points from something I read.

8. Taking tests that require critical evaluation.

9. Taking essay tests.

10. Reviewing and revising my notes shortly after taking them.

11. Rewarding myself for studying by taking a break.

12. Having a regular place to study.

13. Maintaining a daily schedule of study hours.

14. Having regular, weekly review periods.

15. Having a place to study without distractions.

16. Treating myself after doing well on a test.

17. Balancing my study time according to the demands of different classes.

18. Praising myself for doing a good job studying. 
19. Making an outline of material covered in a course.

20. Evaluating my progress at each step.

21. Using a dictionary.

22. Using a computer reference system at the library.

23. Using a thesaurus.

24. Using the reference books at the library.

25 . Using the card catalogue at the library.

26. Doing well in school.

27. Relating what I read to other information.

28. Reading assignments out loud before handing them in.

29. Asking a friend to read my work before handing it in.

30. Completing assignments on time.

31. Making up possible test questions from notes and readings.

32. Summarizing what I read in my own words.

\section{References}

Ames, C., \& Archer, J. (1988). Achievement goals in the classroom: Students' learning strategies and motivation processes. Journal of Educational Psychology, 80, 260-267.

Andrich, D. (1978). A rating formulation for ordered response categories. Psychometrika, 43, 561-573.

Bandura, A. (1986). Social foundations of thought and action: A social cognitive theory. Englewood Cliffs, NJ: Prentice Hall.

Borkowski, J. G., Carr, M., Rellinger, E. A., \& Pressley, M. (1990). Self-regulated strategy use: Interdependence of metacognition, attributions, and self-esteem. In B. F. Jones (Ed.), Dimensions of thinking: Review of research (pp. 53-92). Hillsdale, NJ: Lawrence Erlbaum.

Boyle, S. L. (1997). Explanation of subject-specific academic achievement via self-regulated learning strategies. Paper presented at the annual meeting of the American Educational Research Association, Chicago.

Brown, A. L., Bransford, J. D., Ferrara, R. A., \& Campione, J. C. (1983). Learning, remembering, and understanding. In J. H. Flavell \& E. H. Markman (Eds.), Handbook of child psychology, Vol. 3, Cognitive development (pp. 177-266). New York: John Wiley.

Douzenis, C. (1997). The relationship of quality of effort and estimate of knowledge gain among community college students. Community College Review, 24(3), 27-35.

Greene, B. A., \& Miller, R. B. (1996). Influences on course achievement: Goals, perceived ability, and cognitive engagement. Contemporary Educational Psychology, 21, 181-192.

Grunder, P. G., \& Hellmich, D. M. (1997). Academic persistence and achievement of remedial students in a community college success program. Community College Review, 24(2), 21-33.

Harris, K. R., \& Pressley, M. (1991). The nature of cognitive strategy instruction: Interactive strategy construction. Exceptional Children, 57(5), 392-404.

Linacre, J. M., \& Wright, B. D. (1995). BIGSTEPS computer program. Chicago: MESA.

Lusardi, M. M., \& Smith, E. V., Jr. (1997). Development of a scale to assess concern about falling and applications to treatment programs. Journal of Outcome Measurement, 1, 34-55.

Meece, J. L., Blumenfeld, P. C., \& Hoyle, R. H. (1988). Students' goal orientations and cognitive engagement in classroom activities. Journal of Educational Psychology, 80, 514-523.

Miller, R. B., Behrens, J. T., Greene, B. A., \& Newman, D. (1993). Goals and perceived ability: Impact on student valuing, self-regulation and persistence. Contemporary Educational Psychology, 18, 2-14. 
Miller, R. B., Greene, B. A., Montalvo, G. P., Ravindran, B., \& Nichols, J. D. (1996). Engagement in academic work: The role of learning goals, future consequences, pleasing others, and perceived ability. Contemporary Educational Psychology, 21, 388-422.

Nicholls, J. G. (1989). The competitive ethos and democratic education. Cambridge, MA: Harvard University Press.

Nolen, S. B. (1988). Reasons for studying: Motivational orientations and study strategies. Cognition and Instruction, 5, 269-287.

Pajares, F. (1996). Self-efficacy beliefs and mathematical problem solving of gifted students. Contemporary Educational Psychology, 21, 325-344.

Pajares, F., \& Miller, D. (1994). Role of self-efficacy and self-concept beliefs in mathematical problem solving: A path analysis. Journal of Educational Psychology, 86, 193-203.

Pintrich, P. R., \& DeGroot, E. V. (1990). Motivational and self-regulated learning components of classroom academic performance. Journal of Educational Psychology, 82, 33-40.

Pintrich, P. R., \& Garcia, T. (1991). Student goal orientation and self-regulation in the college classroom. In M. L. Maehr \& P. R. Pintrich (Eds.), Advances in motivation and achievement (Vol. 7, pp. 371-401). Greenwich, CT: JAI.

Pressley, M. (1995). More about the development of self-regulation: Complex, long-term and thoroughly social. Educational Psychologist, 30, 207-212.

Pressley, M., Borkowski, J. G., \& Schneider, W. (1987). Cognitive strategies: Good strategy users coordinate metacognition and knowledge. In R. Vasta \& G. Whitehurst (Eds.), Annals of child development (Vol. 4, pp. 89-129). Greenwich, CT: JAI.

Ramirez, M. O., \& Owen, S. V. (1991, April). Scale revision of the Study Skills Self-Efficacy Instrument. Paper presented at the annual meeting of the New England Educational Research Association, Portsmouth, $\mathrm{NH}$.

Schmeck, R., Ribich, F., \& Ramanaiah, N. (1977). Development of a self-report inventory for assessing individual differences in learning process. Applied Psychological Measurement, 1, 413-431.

Schunk, D. H. (1991). Self-efficacy and academic motivation. Educational Psychologist, 26, 207-231.

Silver, B. B., Gable, R. K., \& Smith, E. V. (1995, October). Study skills self-efficacy of community-technical college students. Paper presented at the annual meeting of the Northeastern Educational Research Association, Ellenville, NY.

Silver, B. B., Gunther, L., Smith, E. V., \& Owen, S. V. (1996, October). Study skills self-efficacy at the community college and university levels: An instrument validation and sample comparison study. Paper presented at the annual meeting of the Northeastern Educational Research Association, Ellenville, NY.

Smith, A. L., Owen, S. V., Reid, B., \& Ramirez, M. O. (1990, May). Measurement of study skills self-efficacy. Paper presented at the annual meeting of the New England Educational Research Association, Rockport, ME.

Tabachnick, B. G., \& Fidell, L. S. (1996). Using multivariate statistics (3rd ed.). New York: HarperCollins College.

Weinstein, C. E., \& Mayer, R. E. (1986). The teaching of learning strategies. In M. Wittrock (Ed.), Handbook of research on teaching (pp. 315-327). New York: Macmillan.

Williams, J. E. (1996). The relations between efficacy for self-regulated learning and domainspecific academic performance, controlling for test anxiety. Journal of Research and Development in Education, 29, 77-80.

Wright, B. D., \& Linacre, M. (1994). Reasonable mean-square fit values. Rasch Measurement Transactions, 8(3), 370.

Wright, B. D., \& Masters, G. N. (1982). Rating scale analysis: Rasch measurement. Chicago: MESA. 
Zimmerman, B. J. (1989). A social cognitive view of self-regulated academic learning. Journal of Educational Psychology, 81, 329-339.

Zimmerman, B. J., \& Bandura, A. (1994). Impact of self-regulatory influences on writing course attainment. American Educational Research Journal, 31, 845-862.

Zimmerman, B. J., Bandura, A., \& Martinez-Pons, M. (1992). Self-motivation for academic attainment: The role of self-efficacy beliefs and personal goal setting. American Educational Research Journal, 29, 663-676.

Zimmerman, B. J., \& Martinez-Pons, M. (1990). Student differences in self-regulated learning: Relating grade, sex, and giftedness to self-efficacy and strategy use. Journal of Educational Psychology, 82, 51-59. 